7th International Symposium on Superalloy 718 and Derivatives Edited by: E.A. Ott, J.R. Groh, A. Banik, I. Dempster, T.P. Gabb, R. Helmink, X. Liu, A. Mitchell, G.P. Sjöberg, and A. Wusatowska-Sarnek TMS (The Minerals, Metals \& Materials Society), 2010

\title{
EFFECT OF THERMOMECHANICAL WORKING ON THE MICROSTRUCTURE AND MECHANICAL PROPERTIES OF HOT PRESSED SUPERALLOY INCONEL 718
}

\author{
Andrzej Nowotnik, Jan Sieniawski \\ Department of Materials Science, Rzeszow University of Technology, \\ W. Pola 2 Str., 35-959 Rzeszów, Poland \\ Keywords: Superalloy, Inconel 718, Dynamic Precipitation, Hot Working
}

\begin{abstract}
Experimental results on hot deformation and dynamic structural processes of nickel based alloy Inconel 718 are reviewed. The focus is the analysis of dynamic precipitation processes which operate during hot deformation of these materials at elevated temperatures. Hot compression tests were performed on the solution treated precipitation hardenable nickel based superalloy Inconel 718 at $720-1150^{\circ} \mathrm{C}$ with a constant true strain rates of $10^{-4}$ and $4 \times 10^{-4} \mathrm{~s}^{-1}$. True stress true strain curves and microstructure analysis of the deformed nickel based superalloy is presented. The properties and dynamic behaviour are explained through observation of the microstructure using standard optical, scanning and transmission electron microscopy. Structural observations of solution treated Inconel 718 deformed at high temperatures, reveal non uniform deformation effects. The distribution of niobium-rich carbides were affected by localized flow within the strain range investigated at relatively low deformation temperatures $720-850^{\circ} \mathrm{C}$.
\end{abstract}

\section{Introduction}

The capability of material to undergo plastic deformation is one of the most exceptional characteristics of metals and alloys. This capability is utilized in most forming operations to obtain the required final shape for many products. Obtaining the appropriate microstructure that guarantees suitable properties for the final product is the main goal of most forming operations. Subsequently chemical and phase composition, microstructure and technique of deformation or even its parameters plays a crucial role in the plastic deformation process. These factors affect the strengthening kinetics, the microstructure and thus the mechanical properties of a material. Cold and hot-working are the most frequently used techniques for forming metals and alloys. During cold-working, intermediate annealing is repeatedly required to remove the work hardening effect through recovery and recrystallization of the material. Both processes occur not only under static conditions but also under dynamic conditions in addition, i.e. during high temperature deformation. During the last decade the mechanisms involved in hot-working of metals and alloys have been extensively investigated. The most common softening mechanisms include dynamic recovery (DR) and dynamic recrystallization (DRX). At relatively low strain rates a precipitation process may operate during hot deformation of solution treated age hardenable alloys. This phenomenon is known as dynamic precipitation (DP), and is defined as precipitation during deformation of solution treated alloys below the solvus temperature. DP may interact with other structural processes during hot deformation and has an effect on the flow stress as well as the final microstructure and thus the properties of the material. DP usually increases the total hardening of the material due to retardation of both DR and DRX by dispersive particles growth. The amount of strengthening during hot deformation resulting from 
dynamically precipitated particles depend on their morphology, strength and distribution within the matrix. During hot deformation of age hardenable alloys the change of particle distribution and their morphology may also affect the microstructure and material properties. In particular, particle morphology may be affected by the dynamic coarsening of precipitates which might develop during hot deformation of some alloys.

A fundamental feature of plastic deformation is the homogeneity of strain distribution. It is commonly accepted that at low temperatures and high strains, flow localization may develop and affect the material ductility. On the other hand, hot-deformation at intermediate temperatures may also result in localized plastic flow and nonhomogenous deformation. Flow localization, as a result of substructure instability and collective motion of a large number of dislocations characterizes coarse slip or shear banding, Luders bands and the Portevin-LeChatelier effect. Kink bands and mechanical twins may also be considered as an individual form of flow localization. Coarse slip is usually used to describe the localized flow within individual grains, whereas shear bands traverse many grains very often without any significant relation to the position of easy glide systems plane. In pure metals and single phase alloys, shear bands have been found to be preferential sites for the nucleation of both static and dynamic recrystallization. It is widely believed that in age hardenable alloys, shear bands and dislocation substructure produce preferred sites for nucleation of precipitates, thus enhancing the nucleation. These same features also are believed to enhance the particle growth rate during hot deformation as a result of higher vacancy concentration produced by intensive straining as well as increased dislocation pipe diffusion. The study of processes which are associated with dynamic aging of supersaturated solid solution during hot deformation may turn out to be very complicated because of the mutual interaction between dynamic precipitation and the structure resulting from the deformation process.

The stress-strain curves for metals and alloys obtained during hot deformation are typically characterized by an initial hardening followed by either steady-state flow, single-peak or multipeaks behavior depending on the material, deformation temperature and strain rate. It has been reported that for materials which display steady-state flow after an initial hardening range, the flow stress level was controlled by a sole DR process. Generally, $\sigma-\varepsilon$ characteristic with the flow stress increasing to a peak (initial strain hardening) and then decreasing to a steady state is typical for hot working accompanied by DRX. The modification of particle morphology and/or the material texture may also result in the development of a flow stress peak. Localized plastic flow has been found to be responsible for flow softening after the initial peak in some hot deformed materials. Therefore flow softening can not be used for a simple DRX detection and careful structural observations should always be performed to analyze structural processes which are responsible for the material softening during hot deformation.

The contribution of flow localization to the strain hardening or flow softening and the flow stress-strain behavior during hot deformation of precipitation hardenable alloys is still a subject of extensive research. The interaction between the flow localization and dynamic precipitation process has been the subject of very limited research [1-13]. For instance, the retardation of dynamic recrystallization due to dynamic precipitation was tested for HSLA steels [4-7]. It should be noted that the deformation process in HSLA steels have been assumed to be homogeneous. However, the homogeneity of the deformation was not examined during the research cited.

There is a shortage of data which refer to specific features of phase transformation processes in precipitation hardenable alloys. Moreover, the existing data does not allow generalizing structural features of DP and simplifying structural description of the process. 
The experiments on hot deformation of age hardenable alloys and the analysis of DP process have a practical aspect. This interaction could become an important feature of high temperature performance and may also the production of specific structures of materials.

Inconel 718 is relatively the largest nickel base alloy since its commercial utilization in 1965. It is a nickel based precipitation hardenable alloy, containing major additions of $\mathrm{Fe}, \mathrm{Nb}$ and Mo. Minor contents of $\mathrm{Al}$ and Ti are also present. Inconel 718 combines good corrosion and high mechanical properties with excellent weldabilitty. It is used in parts of gas turbines, rocket engines, turbine blades, and in extrusion dies. Superalloy Inconel 718 is extensively used for in aerospace industry especially in high temperature applications. It has been also widely employed in power and nuclear industry. Due to its relatively high mechanical properties and microstructural stability at elevated temperature it has also found its place in the automobile industry. It is used for parts in the turbocharger. The most important method of increasing its mechanical properties is through precipitation hardening. Good mechanical properties of the Inconel 718 can be achieved by choosing proper heat treatment parameters. It is important to produce the optimum distribution of the precipitate, phase characterized by uniform and suitable particulate size. The precipitation hardening process consists of solution annealing, quenching and aging heat treatment..

\section{Material}

In order to investigate the effect of the hardening phases on hot deformation behaviour, the uniaxial, isothermal compression tests at different temperatures and two strain rates were conducted on the solution treated precipitation hardenable nickel based superalloy Inconel 718 of composition given in table 1 .

Table 1. Chemical composition of Inconel 718 (wt.\%)

\begin{tabular}{ll}
\hline $\mathrm{C}$ & 0.0197 \\
$\mathrm{P}$ & $<0.011$ \\
$\mathrm{~S}$ & 0.0064 \\
$\mathrm{Cr}$ & 17.957 \\
$\mathrm{Si}$ & 0.0640 \\
$\mathrm{Nb}$ & 4.5880 \\
$\mathrm{Co}$ & 0.0527 \\
$\mathrm{Zr}$ & 0.0159 \\
$\mathrm{Ta}$ & 0.0221 \\
$\mathrm{Ti}$ & 0.8734 \\
$\mathrm{Fe}$ & 16.665 \\
$\mathrm{Mo}$ & 2.6400 \\
$\mathrm{Al}$ & 0.4917 \\
$\mathrm{Mn}$ & 0.0537 \\
$\mathrm{~V}$ & 0.0137 \\
$\mathrm{~W}$ & 0.01322 \\
$\mathrm{Ni}$ & balance \\
\hline
\end{tabular}


Shear band development and flow localization is expected during hot deformation of Inconel 718 alloy which affects both mechanical behaviour and microstructural features. Precipitation occurs during aging while the samples are compressed making the alloy suitable for studying the interaction of flow localization and dynamic precipitation process. To intensify these phenomenons the alloy has been compressed at two relatively low constant strain rates $\left(10^{-4}\right.$, $4 \times 10^{-4} \mathrm{~s}^{-1}$ ) within the temperature range corresponding to temperatures of precipitation of the hardening phase up to a true strain of 1.9. Elongated compression testing made it possible to reach sufficient deformation and deformation time required for diffusion to control processes developing during the deformation test. Computer-controlled, Gleeble test equipment was used for the compression test. The cubicoidal samples $(20 \times 10 \times 20 \mathrm{~mm})$ were conductive heated to $1150^{\circ} \mathrm{C}$ at heating rate of $3^{\circ} \mathrm{C} / \mathrm{s}$, held for $300 \mathrm{~s}$ and finally cooled to the compression temperature. The temperature was controlled by a type $\mathrm{K}$ thermocouple inserted and welded in an opening hollowed out in the central part of the sample by spark erosion technique. Three additional thermocouples were used to acquire the distribution of the temperature from one of the faces to the centre of the specimen. A combination of graphite and molybdenum foils was used to reduce the friction between the anvils and the specimen as well as the gradient of temperature along the specimen. The deformation for all the tests was controlled by the stroke and measured by means of a loadcells attached to the jaws. The tests were carried out in an argon atmosphere. The flow stress values under two different low strain rates over a range of temperatures (720$1150^{\circ} \mathrm{C}$ ) were measured. Additionally the microstructure was examined using standard optical and electron microscopy techniques, SEM (Hitachi S-3400) and TEM (STEM) - (Jeol 2100).

The present research work contributes some new information about the precipitation process which occurs in solution treated nickel based superalloy deformed at elevated temperatures and was inspired by the studies of previous researches performed on $\mathrm{Cu}-\mathrm{Ni}-\mathrm{Si}-\mathrm{Cr}-\mathrm{Mg}, \mathrm{Cu}-\mathrm{Ti}$ and low carbon steel [1-6,14,20]. The strain/precipitation interaction have revealed much more complex structural processes than those reported for HSLA steels [4]. Non-uniform deformation was observed during hot deformation particularly, which was found to have an effect on dynamic structural processes and, consequently, the structure and mechanical properties of the hot deformed alloys. The plastic instability resulted from the interaction of discontinuous precipitation and shear bands development. The flow localization was accompanied by dynamic particles coarsening within shear bands. The flow stress-strain behavior of $\mathrm{Cu}-\mathrm{Ni}-\mathrm{Cr}-\mathrm{Si}-\mathrm{Mg}$ alloy was affected and controlled by dynamic precipitation and its interaction with the strain localization. Additionally, the dynamic coarsening within shear bands was reported to be responsible for further flow softening during hot compression of the material. The shearing process was found to be a self-induced one, i.e. the flow localization accelerated discontinuous precipitation and the precipitation coarsened within the sheared area, which promoted further flow softening. In order to test the interaction of deformation with the precipitation process, hot compression tests were performed on the nickel based superalloy Inconel 718. In718 alloy was chosen since it is hardenable and therefore suitable for testing continuous precipitation interaction with deformation during hot deformation. Thus, the purpose of the described experiments was to study the mechanical behavior and related structural changes that take place during hot deformation of supersaturated Inconel alloy below the solvus temperature (dynamic precipitation conditions). Emphasis was placed on the interaction of precipitation with structural inhomogeneties that may develop during hot deformation. The main goal was to answer the question if the precipitation affects the deformation mode and, if nonuniform deformation induces dynamic coarsening of particles within shear bands. The experimental results may allow 
a generalized description of the DP process in alloys undergoing multi-step phase transformation including continuous precipitation and discontinuous precipitation.

The effect of deformation temperature on the true stress-true strain curves for the alloy deformed at strain rates of: $10^{-4} ; 4 \times 10^{-4} \mathrm{~s}^{-1}$ and temperatures of $720-1150^{\circ} \mathrm{C}$ is shown in figure 1.

a)

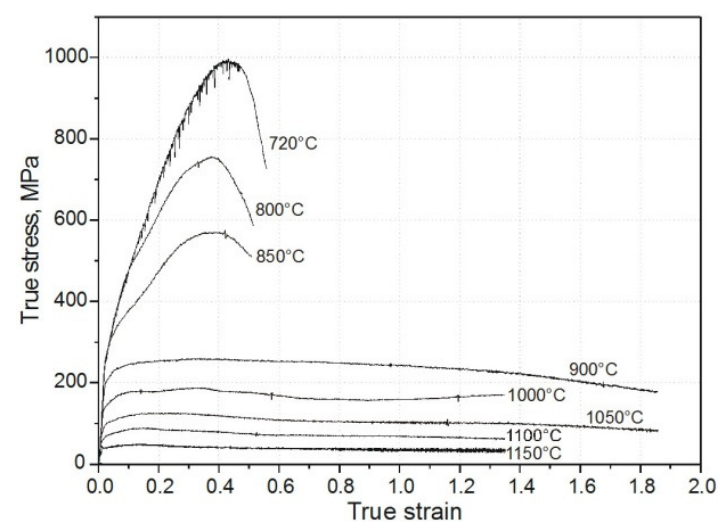

b)

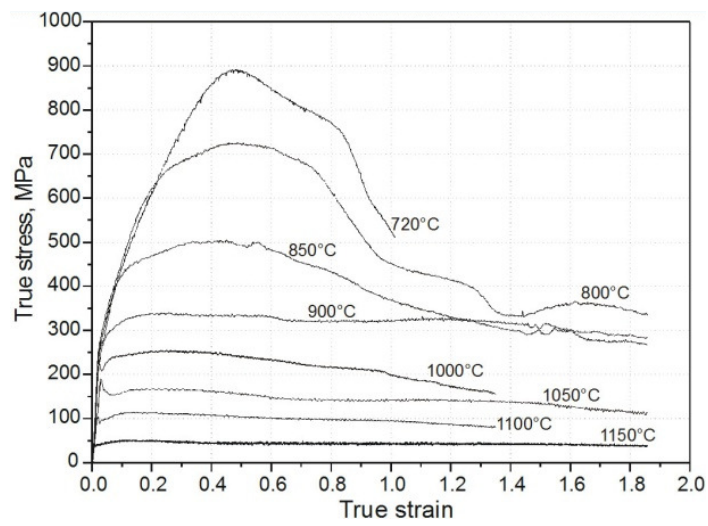

Figure. 1. True stress-true strain curves for Inconel 718 alloy deformed at different temperatures and a strain rate of a) $10^{-4} \mathrm{~s}^{-1}$ and b) $4 \times 10^{-4} \mathrm{~s}^{-1}$ (the deformation temperature was indicated in the figure).

The stress-strain curves for both strain rates evaluated do not give a true indication of a stationary plastic flow in the temperature range $\left(720-850^{\circ} \mathrm{C}\right)$ due to fracture of the samples. The classic interdependence of the flow stress and deformation parameters can be seen, namely: the flow stress increased with decreasing deformation temperature and increasing strain rate. This behavior is similar to the results obtained by Guimaraes and Jonas [21]. One must notice two distinguishable regions on the flow stress curves of the solution treated samples of Inconel alloy deformed at relatively low temperature, namely: 720,800 and $850^{\circ} \mathrm{C}$ and with strain rate of $10^{-4}$ $\mathrm{s}^{-1}$ (see Fig. 1). The first region, which occurs at an applied strain not exceeding 0.4, is characterized by almost uniform work hardening to a hump due to effective static precipitation within the alloy. The second region is characterized by a rapid flow softening followed by sample fracture at strain not exceeded the value of $\varepsilon \approx 0.6$ (Fig. 1). However, the flow stress of the samples deformed at these temperatures with higher strain rate $\left(4 \times 10^{-4} \mathrm{~s}^{-1}\right)$ increased to a peak value and then rapidly decreased as the strain further increased (Fig. 1b). The typical structure of the solution treated Inconel sample deformed at $720^{\circ} \mathrm{C}$ with both strain rates is shown in Fig. 2. Coarse slip bands in the grain interiors and localized flow shear bands were observed. Non-uniform deformation and coarse slip bands were also observed in the microstructure of the samples of Inconel 718 deformed at 800 and $850^{\circ} \mathrm{C}$ (Fig. 3).

Development of cracks followed by fracture in the flow softening range was also observed in the alloy deformed at these deformation temperatures but at higher strain rate of $4 \cdot 10^{-4} \mathrm{~s}^{-1}$. However, the effect was limited to the central part of the compressed sample and did not cause a failure of the sample before reaching its imposed maximum strain, as occurred in the samples deformed at the same temperatures $\left(720-850^{\circ} \mathrm{C}\right)$ with the lower strain rate $4 \times 10^{-4} \mathrm{~s}^{-1}$. 
a)

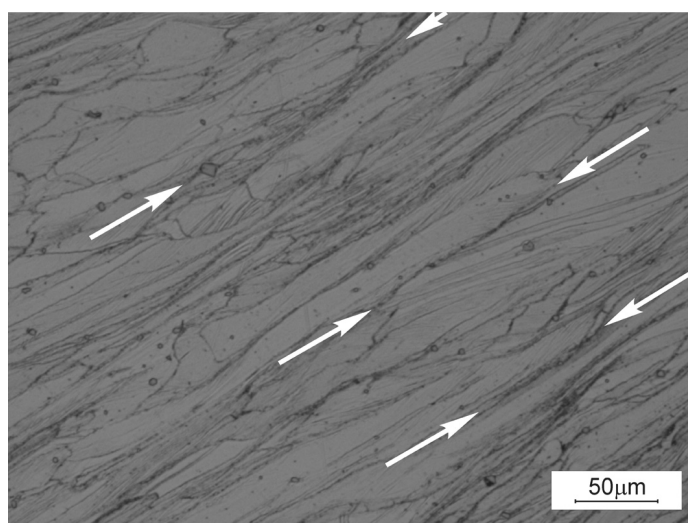

b)

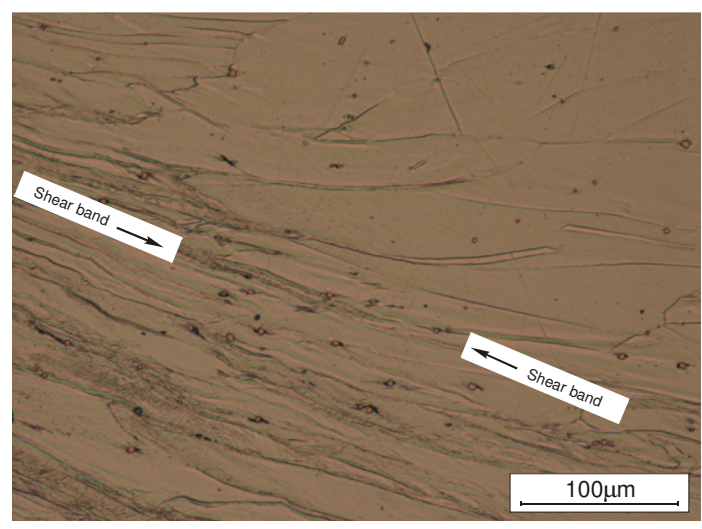

Figure. 2. Optical micrograph for the sample of $\operatorname{In} 718$ deformed at $720^{\circ} \mathrm{C}$, strain rate of a) $\left.=10^{-4} \mathrm{~s}^{-1} \mathrm{i} \mathrm{b}\right)=4 \times 10^{-4} \mathrm{~s}^{-1}$.

a)

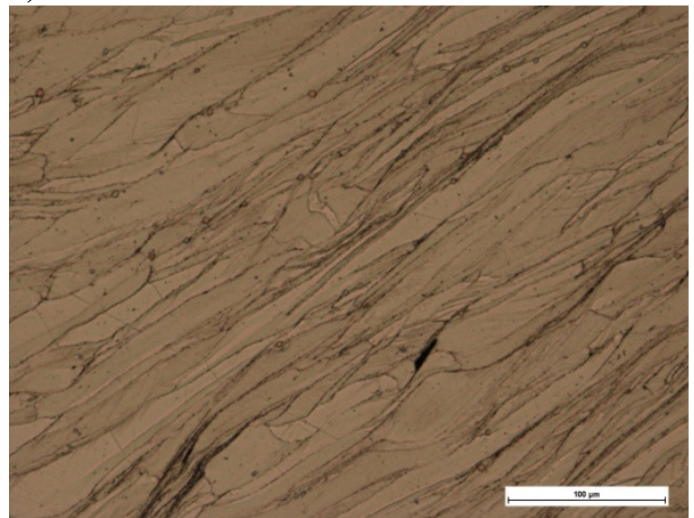

b)

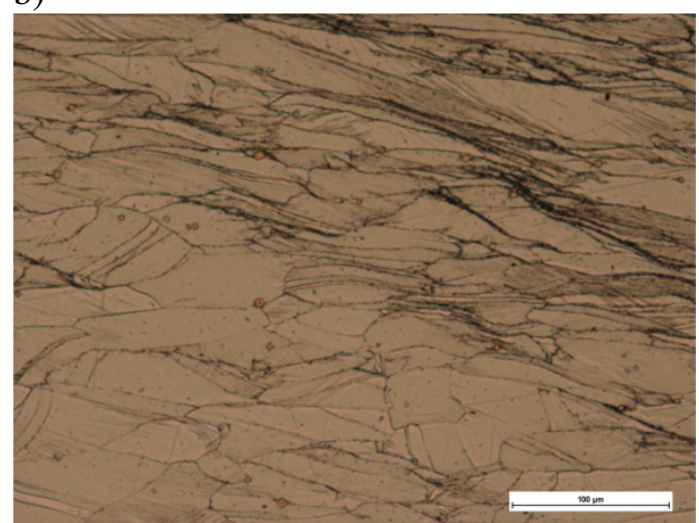

Figure. 3. Micrograph of the alloy deformed at $800^{\circ} \mathrm{C}$, strain rate of a) $10^{-4} \mathrm{~s}^{-1}$ and b) $4 \times 10^{-4} \mathrm{~s}^{-1}$.

Microstructural examinations of the samples revealed sites where preliminary flow localization caused localization of the hardening phases. One can see on the micrographs of the Inconel alloy deformed at $720^{\circ} \mathrm{C}$ at both strain rates columnar particles distributed along shear bands (see regions marked with arrows in the figures 2 and 3). Microshear bands may induce localized shearing within neighbouring grains due to the local stress concentration at the grain boundary which results in shear band development throughout those grains. As seen in the elemental maps in Fig. 4, the regions enriched in $\mathrm{Nb}$ correspond to the formation of $\mathrm{NbC}$ precipitates. 

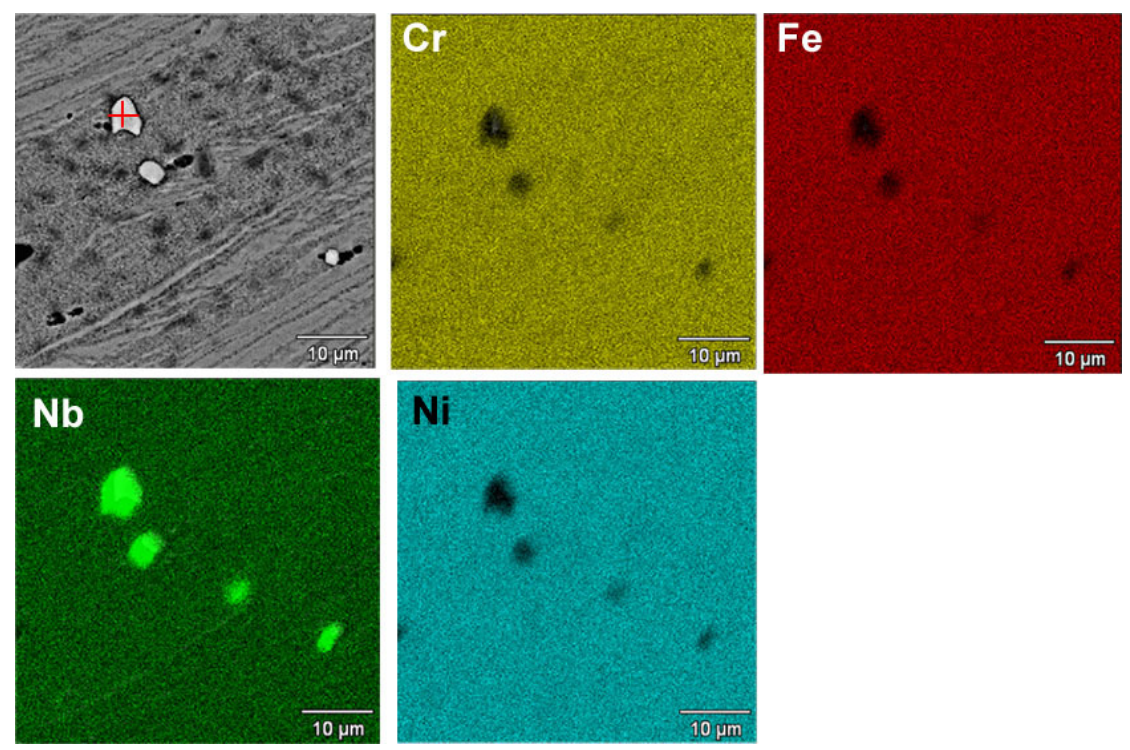

Figure. 4. Elemental maps of precipitates in Inconel 718 alloy deformed AT $800^{\circ} \mathrm{C}$ and strain rate of $4 \times 10^{-4} \mathrm{~s}^{-1}$

Fig. 5 shows a typical EDS spectrum of the particle from Fig. 4 (marked with red cross), from which it can be preliminarily concluded that the precipitate contains $\mathrm{Nb}$, which is carbide formers, but contained appreciable amounts of $\mathrm{Cr}, \mathrm{Fe}$ and $\mathrm{Ni}$ in addition to Ti. The presence of $\mathrm{Cr}, \mathrm{Fe}$ and $\mathrm{Ni}$ in the EDS spectrum may be associated with matrix elements, or could be attributed to the nature of the carbides.

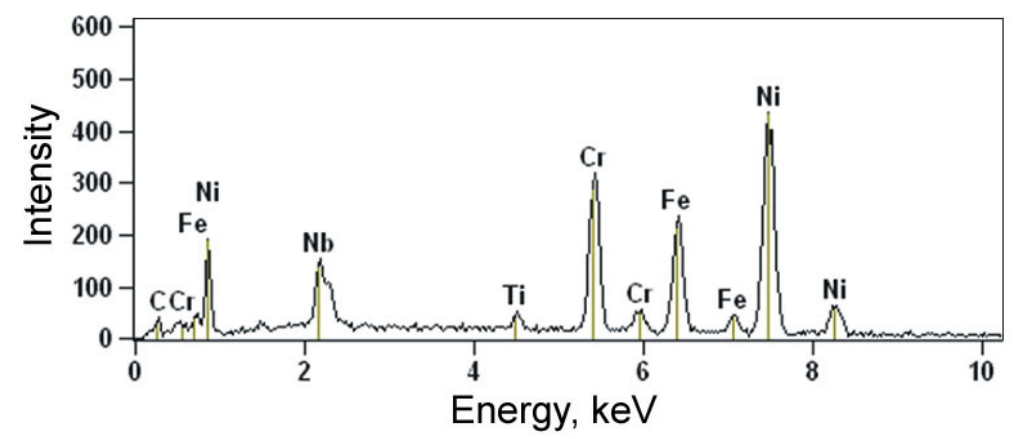

Figure. 5. EDS-spectra acquired in positions indicated by the red cross in Fig. 4

Further confirmation of the carbides was needed and was carried out by TEM studies. TEM observations of the samples deformed at 720 and $850^{\circ} \mathrm{C}$ with both strain rates confirmed that localized deformation may promote intensive dynamic precipitation and coarsening of the particles within shear bands (Fig. 7 and 8). In conformance with the findings from scanning electron microscope SEM, Nb-rich carbides were observed by TEM. These carbides are usually of irregular shape and were most often found within shear bands. The carbide is shown in Fig. 6 along with a diffraction pattern from the particle and its surrounding matrix. The particle contained mainly $\mathrm{Nb}$, with a small amount of $\mathrm{Ti}$ and $\mathrm{Cr}$. It has a cubic structure with lattice parameter $\mathrm{a}=0.43 \mathrm{~nm}$, which matched well with the $\mathrm{Nb}$-type carbides $(\mathrm{a}=0.44 \mathrm{~nm})$ reported by Wilson [23]. 
a)

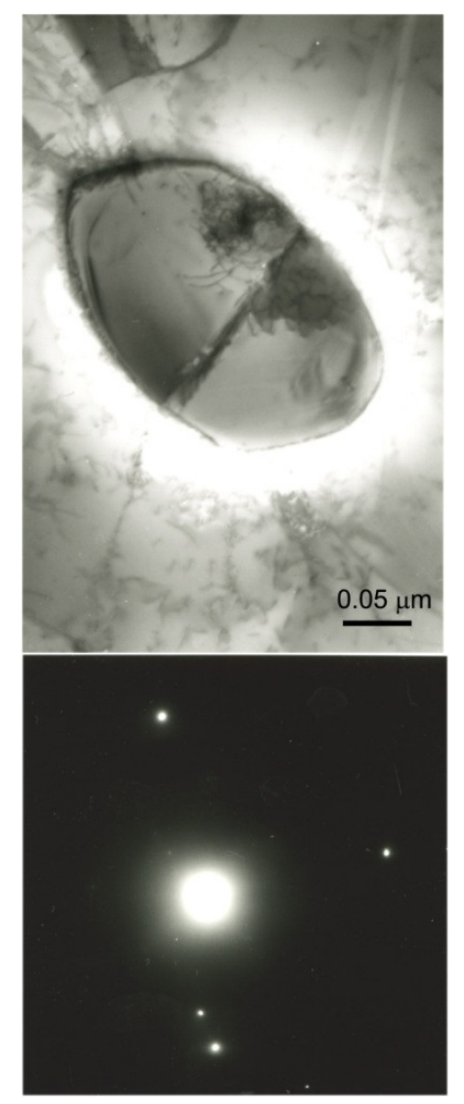

b)
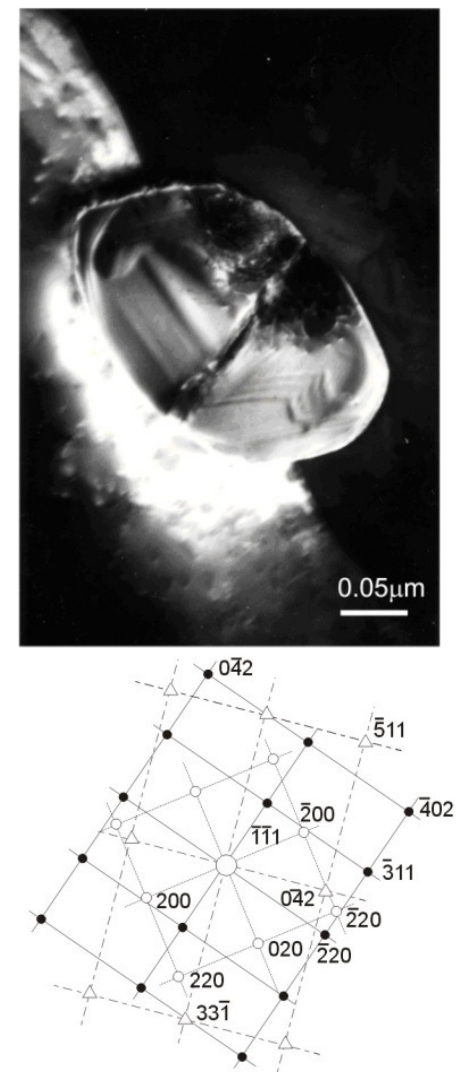

$\longrightarrow: \gamma(3.6 \AA \bar{A})-[112]$

$\gamma(3.6 \AA)-[001]$

$\mathrm{NbC}(4.3 \mathrm{~A})-[116]$

d)

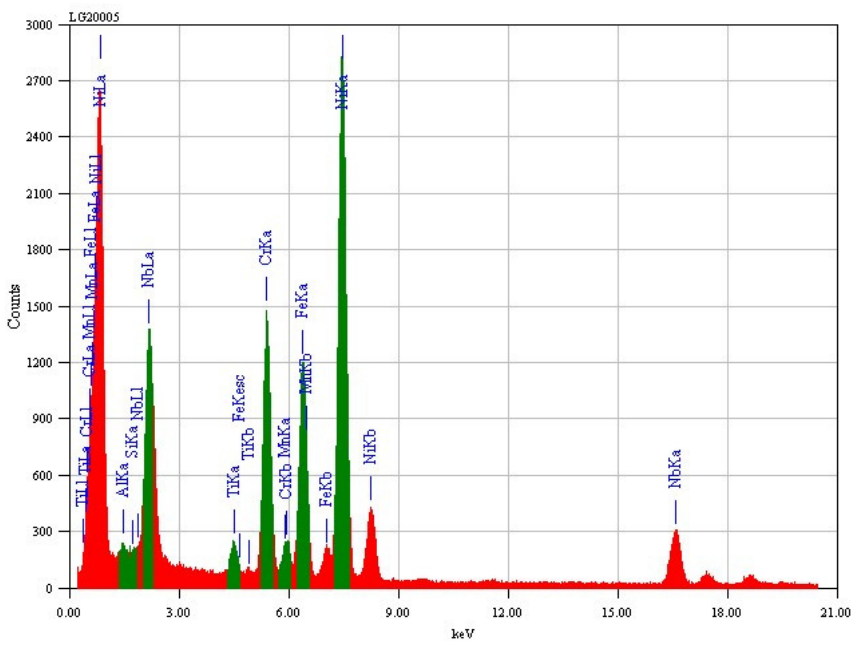

Figure. 6. Nb-rich carbides in the sample of Inconel 718 deformed at $720^{\circ} \mathrm{C}$ with strain rate of $10^{-4} \mathrm{~s}^{-1}$; a) TEM bright field, b) TEM dark field, c) indexed diffraction pattern (SADP) - zone axis was [-111], d) EDS spectra of analyzed particle.

There is no crystallographic orientation relationship between particle and the matrix. Similar particles were often observed within the localized flow areas of deformed microstructure of the examined Inconel. These examinations indicate that the particles are associated with secondary $\mathrm{NbC}$. The crystallographic orientation of the particles appears to be related to that of the matrix on one side of the shear band. Based on the diffraction from the particle and its surrounding matrix, the following matrix-particle relationships were obtained: 


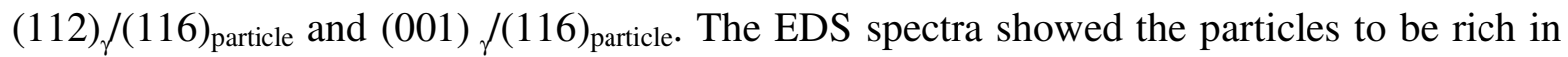
$\mathrm{Nb}$, but also contained some amounts of $\mathrm{Ti}, \mathrm{Cr}$ and $\mathrm{Fe}$. EDS linear analysis from a typical, large particle showed that this type of particle contained mainly $\mathrm{Nb}$, which indicates that these particles are NbC carbides (Fig. 6e).

a)

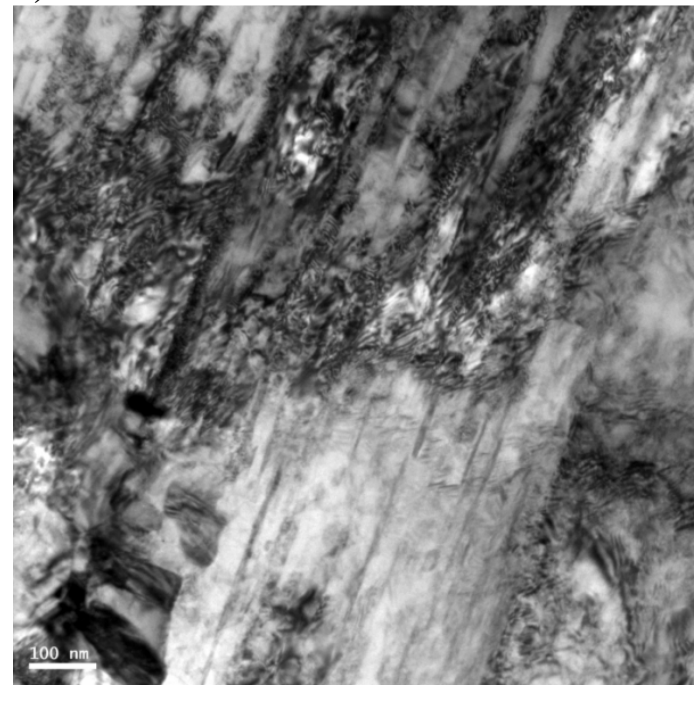

b)

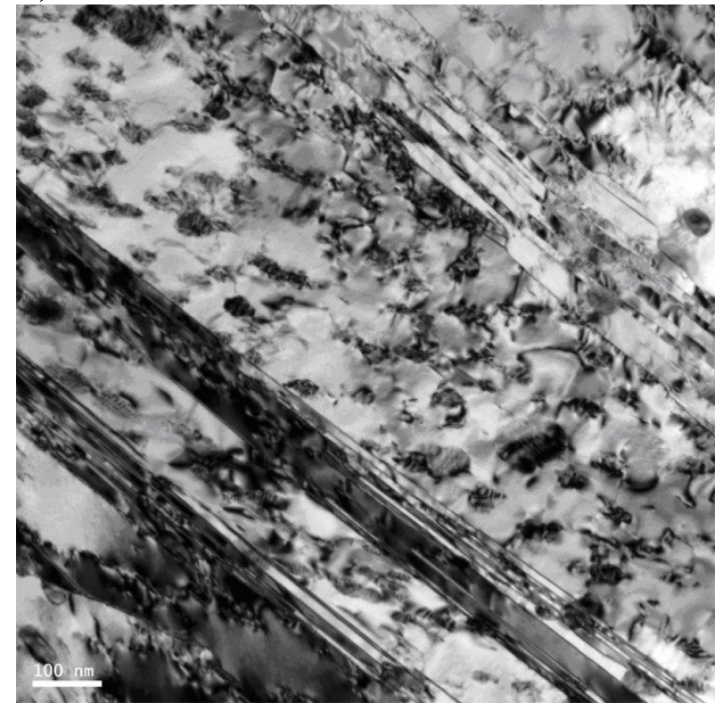

Figure. 7. Microstructure of solution treated samples deformed to 1.8 true strain at $800^{\circ} \mathrm{C}$, strain rate of $10^{-4} \mathrm{~s}^{-1}$.

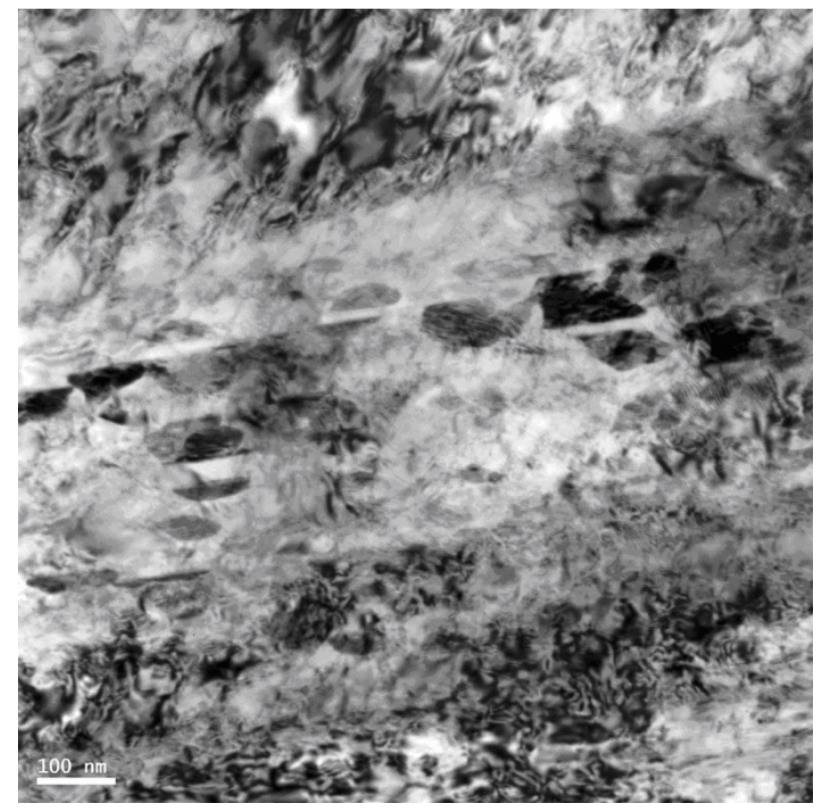

Figure. 8. Microstructure of the alloy subjected to compression test at $850^{\circ} \mathrm{C}$, strain rate of $4 \cdot 10^{-4} \mathrm{~s}^{-1} \cdot \gamma^{\prime \prime}$ phase precipitation in the matrix and carbides phase precipitation within shear band.

A steady state flow stress range, following the flow stress maximum, was observed during high temperature deformation $\left(900,1000,1050,1100\right.$ and $1150^{\circ} \mathrm{C}$ ) (figs. 1). A single peak stressstrain curve observed at high temperatures has resulted from dynamic recrystallization. The 
characteristic shape of the stress-strain curves indicated that the structural softening mechanism for the alloy deformed at higher temperatures was limited to the dynamic revocery. However, it was noted that dynamic recrystallization was a process which has a crucial effect on the final value of the flow stress (Fig. 9-13). From this point of view, it seems clear why there was no indication of fracture or flow localization and why no arrangement of precipitations due to heterogeneous deformation was detected.

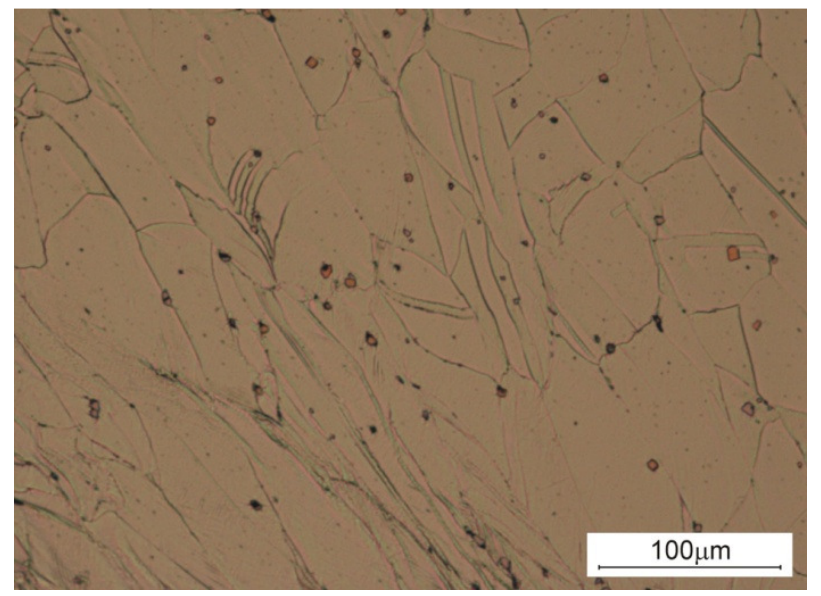

Figure. 9. Optical micrograph for In 718 sample deformed at $900^{\circ} \mathrm{C}$, strain rate of $4 \times 10^{-4} \mathrm{~s}^{-1}$.

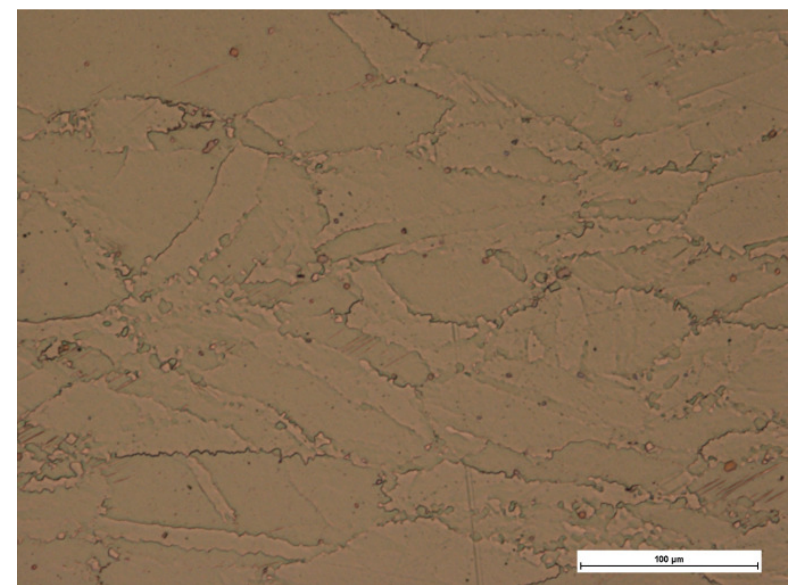

Figure. 10. Optical micrograph for $\operatorname{In} 718$ sample deformed at $950^{\circ} \mathrm{C}$, strain rate

$$
\text { of } 4 \times 10^{-4} \mathrm{~s}^{-1} \text {. }
$$

The transmission electron microscopy of the compressed Inconel 718 confirms the presence of recrystallized grains - see figure 11. 
a)

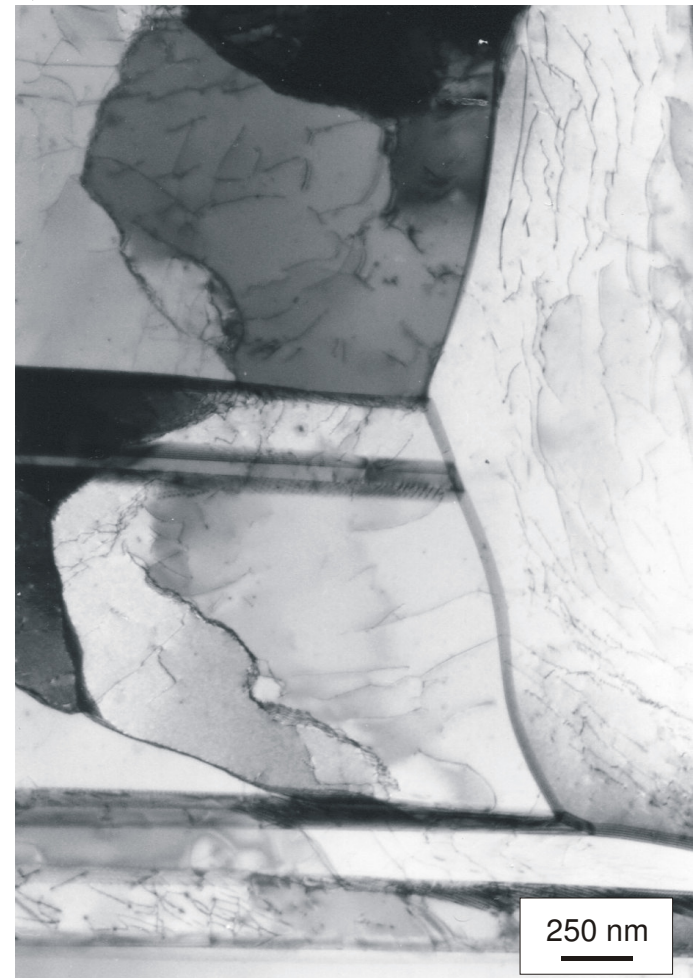

b)

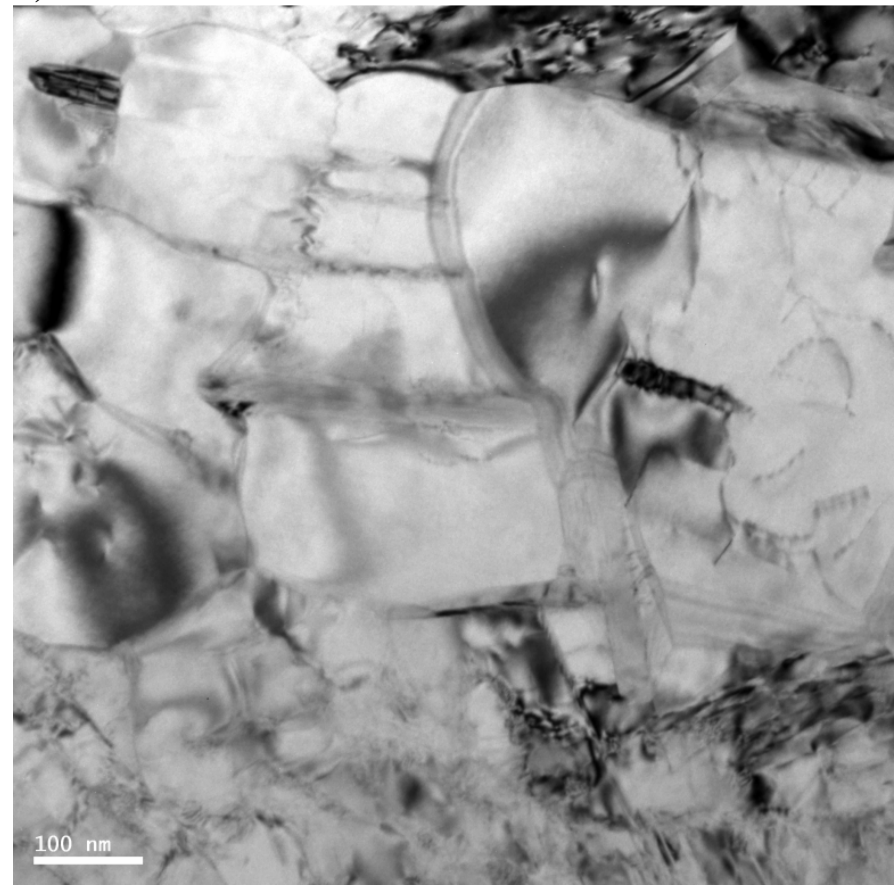

Figure. 11. Coarse recrystallized grains observed by TEM. Sample deformed at $900^{\circ} \mathrm{C}$, strain rate of $4 \times 10^{-4} \mathrm{~s}^{-1}$

a)

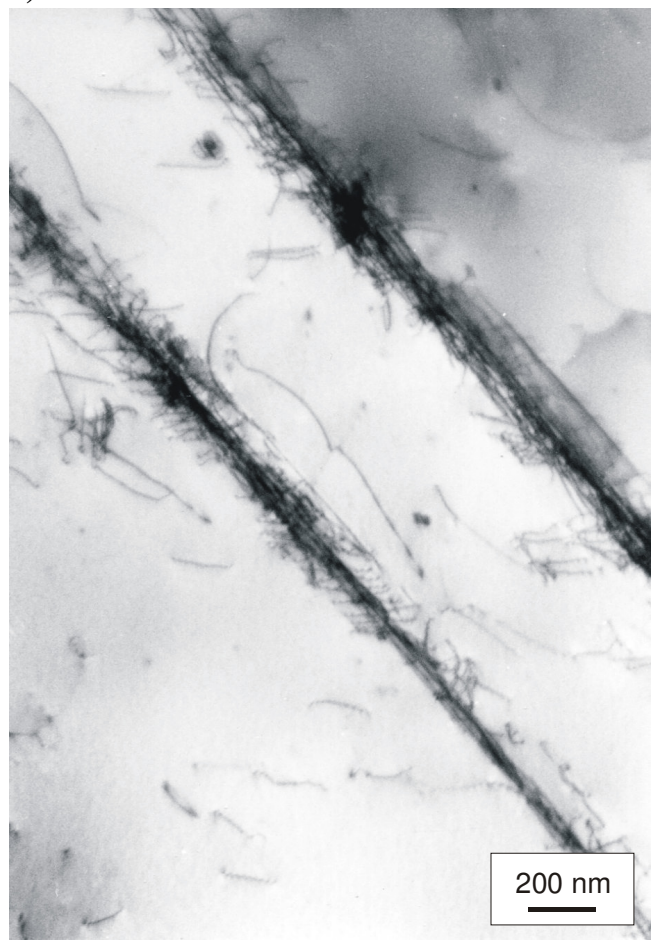

b)

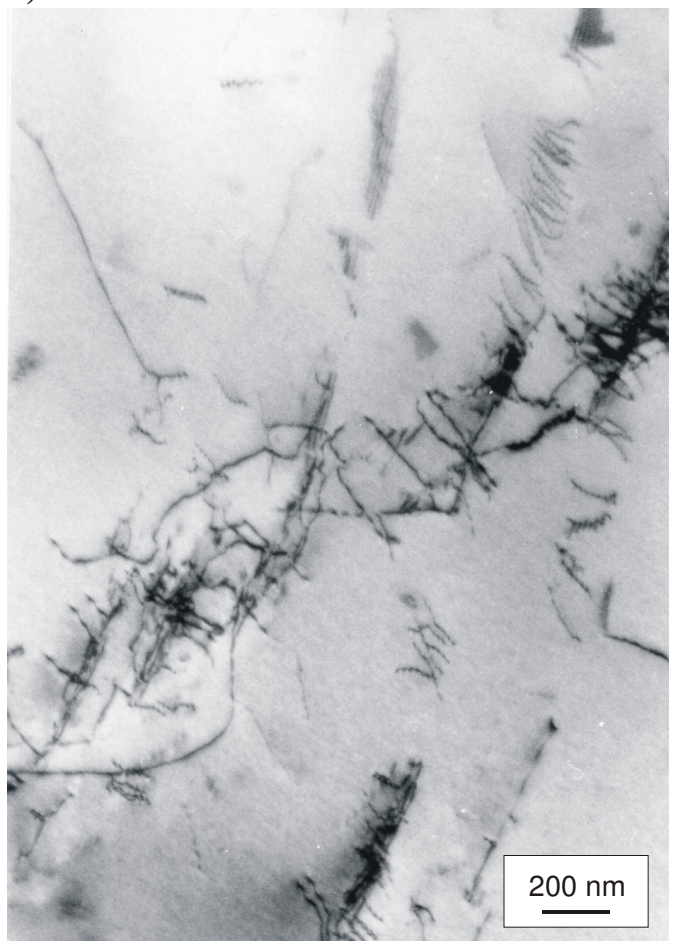

Figure. 12. TEM micrograph of the specimen deformed at $1150^{\circ} \mathrm{C}$, strain rate of $4 \times 10^{-4} \mathrm{~s}^{-1}$. 


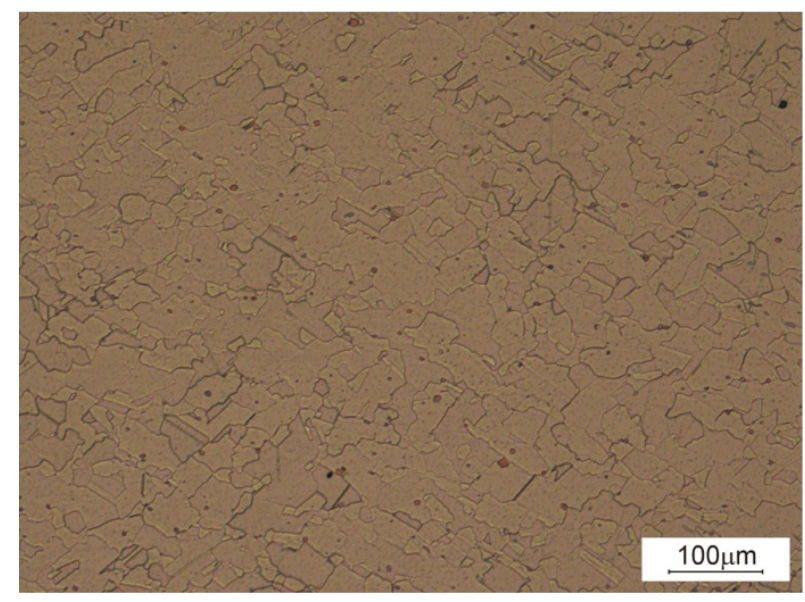

Figure. 13. Optical micrograph for In718 sample of deformed at $1150^{\circ} \mathrm{C}$, strain rate of $10^{-4} \mathrm{~s}^{-1}$.

\section{Conclusions}

The dynamic behavior was explained through observation of the microstructure using standard optical, scanning and transmission electron microscopy.

Structural observations of solution treated Inconel 718 deformed at high temperatures, reveal non uniform deformation effects. The distribution of carbides were affected by localized flow within the strain range investigated at relatively low deformation temperatures $720-850^{\circ} \mathrm{C}$.

It was found that most of the carbides that precipitate within shear bands resulting from on-going deformation process were Nb-rich particles. These are hypothesized to be NbC. Carbides observed with TEM technique were 20 times smaller to those observed by scanning electron microscope SEM. A general conclusion follows from the consideration of the role of shear banding in the material structure - this particular mode of deformation may be used as a method of microstructure control. Oriented arrangement of the secondary phases may significantly reinforce the strength of a material without deterioration of the material ductility, as it was observed in case of $\mathrm{Fe}-\mathrm{Ni}$ [6] and $\mathrm{Cu}$ alloys [1-3]. It is interesting to consider a condition when shear bands are formed in deformed material. These localized fields of internal stresses usually show some spatial distribution with long range periodicity. Since shear bands act as preferred sites for nucleation of second phases, the arrangement of the products of decomposition of unstable matrix should also reflect this periodicity. Hence, one may anticipate in the microstructure of the compressed material linear ordering of hardening phases similar to the distribution of shear bands, as well as their significant influence on the mechanical properties of material.

\section{References}

1. M. Niewczas, E. Evangelista, L. Błaż, ,Strain localization during a hot compression test of Cu-Ni-Cr-Si-Mg alloy", Scripta Metallurgica et Materialia, 27 (1992) 1735-1740.

2. A. A. Hameda, L. Błaż, „Microstructure of hot-deformed Cu-3.45 wt.\% Ti alloy, Materials Science and Engineering, A254 (1998) 83-89. 
3. A. A. Hameda, L. Błaż, „Flow Softening During Hot Compression of Cu-3.45wt.\%Ti Alloy", Scripta Materialia, 12 (1997) 1987-1993.

4. J. J. Jonas, I. Weiss, „Effect of precipitation on recrystallization in microalloyed steels”, Material Science and Engineering, 13 (1979) 238-245.

5. A. Korbel et al., Proceedings: Symposia sponsored by the Extraction and Processing Division, held at the TMS Annual Meeting in Ontario, Florida USA (1997) 301-312.

6. A. Korbel et al., „,The 'natural' metal-matrix composite formation by thermo-mechanical treatments,,, Journal of Materials Processing Technology, 78 (1998) 104-111.

7. A. Nowotnik, L. Błaż, J. Sieniawski, „Phase deformation in $0.16 \%$ C steel under hot deformation conditions" (Paper presented at the Seminar Devoted to the 70th Birthday Anniversary of Prof. Z. Jasieński, Kraków 2005) 213-218.

8. A. Nowotnik, L. Błaż, J. Sieniawski, ,Interaction of phase transformation and deformation process during hot deformation of 0.16\%C steel", Defect and Diffusion Forum, 237-240 (2005) 1240-1245.

9. C.M. Sellars, W.J. Tegart, „La relation entre le resistance et la structure dans la deformation a chaud", Membr. Sci. Rev. Met., 63 (1966) 731-746.

10. S.F. Medina, C.A. Hernandez, ,Modelling austenite flow curves in low alloy and microalloyed steels", Acta Metall., 44 (1996) 137.

11. W.J. Weis in: E.A. Lodia, Superalloy 718 - Metallurgy and Applications, TMS Warrendale, PA (1989) 161.

12. S.C. Madeiros, Y.V.R.K. Prasad, W.G. Frazier, R. Srinivasan, „Microstructural Modeling of Recrystallization in hot working of IN 718 superalloy", Mater. Sci. Eng. A293 (2000) 198207.

13. A. Nowotnik et al., ,Austenite decomposition in carbon steel under dynamic deformation conditions", J. Achievements in Materials Engineering, 20 (2007) 1-2 105-108.

14. C.M. Sellars, W.J. Tegart, ,Progresses in Fracture and Strength of Materials and Structures" Membr. Sci. Rev. Met., 63 (1966) 731-740.

15. X.X. Xia, H.J. Sakaris, H.J. McQueen, „Hot deformation, dynamic recovery and recrystallisation behaviour of aluminium 6061-SiCp composite", Mater. Sci. Technol. 10 (1994) 487-496.

16. B. Lopez, J.J. Urcola, „Hot deformation characteristics of Inconel 625”, Mater. Sc. Technol. 12 (1996) 673-678.

17. W.J. Weis, in: E.A. Loria (Ed.) Superalloy 718 - Metallurgy and Applications: Hot Deformation Behavior of an As-Cast Alloy 718 Ingot TMS, Warrendale, PA (1989) 135-154. 
18. S.C. Medeiros et al., "Microstructural modeling of metadynamic recrystallization in hot working of IN 718 superalloy", Mater. Sci. Eng. A293 (2000) 198.

19. R. Sandstörm, „A model for static recrystallization after hot deformation”, Acta Metallurgica, 23, (1975) 481-489.

20. A.J. Mc Laren, C.M. Sellars, „Modelling distribution of microstructure during hot rolling of stainless steel", Materials Science and Technology, 8 (1992) 1090-1098.

21. A.A. Guimaraes, J.J. Jonas, „Recrystallization and aging effects associated with the high temperature deformation of waspaloy and inconel 718", Metall. Trans. 12 (1981) 1655-1666.

22. C. Slama, M. Abdellaoui, ,Structural characterization of the aged 718”, J. Alloys and Compounds 306 (2000) 277-284.

23. M. Sundararaman, R. Kishore, P. Mukhopadhyay, „Strain hardening in underaged INCONEL 718”, Metallurgical and Materials Transactions 25A (1994) 653-656. 